\title{
Active Commuting to School as a Source of Health Promotion Among Urban Day Secondary School Students in Ibadan, Nigeria: Barriers and facilitators
}

\author{
Adeniyi, A.F., ${ }^{1}$ Ogwumike, O.O., ${ }^{1}$ Ayanleke, E.O., ${ }^{1}$ Maruf, F.A. $^{2}$ \\ ${ }^{1}$ Department of Physiotherapy, College of Medicine, University of Ibadan, Nigeria \\ ${ }^{2}$ Department of Medical Rehabilitation, Faculty of Clinical Sciences and Technology, Nnamdi Azikiwe \\ University, Nnewi, Nigeria
}

Correspondence: adeniyifatai@yahoo.co.uk,fadeniyi@comui.edu.ng

Telephone: +234-8057325888

\begin{abstract}
SUMMARY
This study examined active commuting among secondary school students and the factors that constitute barriers or facilitators. It also assessed whether links exist with sociodemographic characteristics. A selfdesigned questionnaire was used in this cross-sectional survey to obtain data on the commuting patterns, attitudes and sociodemographic characteristics of 926 students in Ibadan, Nigeria. Although $52.7 \%$ of the students lived within 1 to $3 \mathrm{~km}$ of their school, only 19.8\% (183) were active commuters. More than $69 \%$ of the students preferred to remain passive commuters at the expense of good health. Proximity to school was the most reported $(94.5 \%)$ facilitator of active commuting and parental restraint against walking to school was reported by $60.8 \%$ of the passive commuters. Commuting habits were significantly $(\mathrm{p}<0.05)$ associated with sociodemographic characteristics. The students were predominantly passive commuters and their commuting pattern was linked to sociodemographic characteristics while barriers and facilitators of active commuting included family, societal, environmental and school factors.
\end{abstract}

KEYWORDS: adolescents health, attitudes, physical activity, sociodemographic characteristics, transport to school

\section{INTRODUCTION}

Active commuting (walking/bicycling) to school is associated with higher levels of physical activity among children (Robertson-Wilson et al, 2008; Chillón et al, 2010; Pizzaro et al, 2013; Rodríguez-López et al, 2013) and it is a method by which the youth can build physical activity into their daily routines (Babey et al, 2009; Gropp et al, 2012; Owen et al, 2012). Active commuting to school provides opportunities to increase cardiorespiratory fitness (Chillón et al, 2010), prevent obesity (Mendoza et al, 2011), and decrease metabolic disease (Pizzaro et al, 2013). The recent decline in children's active commuting to school (Pizzaro et al, 2013; Lee et al, 2008) has become an important public health issue because positive associations have been observed between active commuting and overall physical activity levels (Lee et al, 2008).
In view of the important role of physical activity in overall health promotion, and in view of the decline in physical activity among children and adolescents (Pizzaro et al, 2013; Lee et al, 2008), it becomes crucial for each society to review all likely opportunities available to promote increased physical activity among their youth. One such opportunity is provided by active commuting to school (Chillón et al, 2010; Pizzaro et al, 2013; Rodríguez-López et al, 2013). The factors influencing active commuting to school are related to multiple factors at multiple levels (Gropp et al, 2012) and they may be as varied as the number of regions or countries being considered. As such, understanding the factors associated with commuting to school will be useful in maintaining a physically active population (Cui et al, 2011). Generally, the factors have been documented to include individual factors, ${ }^{5}$ family 
factors, ${ }^{4-5}$ environmental factors (Babey et al, 2009; Gropp et al, 2012), and policy and community issues (TudorLocke et al, 2001). Before now, issues relating to the commuting of Nigerian secondary school students to and from school, from the perspective of physical activity and health were barely known. A few studies reported the commuting of Nigerian school children, but these were on the bases of road safety and security (Ipingbemi \& Aiworo, 2013), and school dropout rates (Duze, 2010). Previous studies (Chillón et al, 2010; Gropp et al, 2012; Owen et al, 2012; Tudor-Locke et al, 2001; Hume et al, 2009) had recommended the need for further studies to investigate unclear areas within the regions where studies on active commuting had been conducted and to cover new areas where such studies were yet to be conducted. Hence, the purpose of the present study was to determine the homeschool-home commuting practices of a group of Nigerian secondary school students and to investigate the factors that may influence these practices within the Nigerian context.

\section{METHODOLOGY}

The participants for this cross-sectional survey were day students attending co-educational secondary schools in Ibadan North Local Government Area of Oyo State, Nigeria. The city of Ibadan where this study was conducted is located approximately on longitude $3^{\circ} 5^{\prime}$ East of the Greenwich Meridian and latitude $7^{\circ} 23^{\prime}$ North of the Equator, $145 \mathrm{~km}$ east of Lagos city, the former capital of Nigeria (Tomori, 2013). The city's population rose from an estimated 100,000 in 1851 to $1,258,625$ in 1963 and $1,338,659$ in 2006 at an annual growth rate of $2.35 \%$. The total land area of the Ibadan metropolitan area is $3,123 \mathrm{~km}^{2}$ (Tomori, 2013).

The sample size for the study was calculated from the total population of secondary school students in the study area using the equation:

$$
n=N / 1+N\left(e^{2}\right) \quad(\text { Israel, 1992) }
$$

where:

$n$ is the sample size to be determined

$N$ is the population of secondary school students in Ibadan North Local Government Area (approximately $70,000)$

$\mathrm{e}$ is the level of precision (at 0.03).

The computation yielded a total of 1100 students. A sample of 100 was allotted for each school, requiring 11 schools. The relative proportions of private (privately owned) and public (government owned) secondary schools were preserved in the selection process. Hence, a total of five and six schools were randomly selected from the list of the private and public schools respectively. In each of the selected schools, 50 students were randomly selected from each of the junior and senior secondary classes. Boarding students and those with special needs, including physical and mobility challenges were excluded from the study. The selected students were provided with packets containing the consent forms to be completed by the students and their parents; and the active commuting questionnaire to be completed by the students.

A total of $926(84.2 \%)$ out of the 1100 students who received the questionnaire returned it by the end of the study period. The remaining 174 collected the questionnaire but never returned it until the end of the study. These include those who changed their schools, those who graduated without returning their questionnaires, those who decided to withdraw their participation, and those who simply refused to submit their questionnaires in spite of all follow-up efforts.

A self-developed questionnaire (appendix I) was used to collect data on the modes of commuting to school and the reasons for the adoption of such modes. The instrument was developed in stages. The first stage involved the collation of all likely questions from the literature. The questions covered issues of commuting, including the barriers and facilitators of active commuting to school, with due consideration given to the peculiar nature of transportation within the Nigerian context. The questions were later reviewed and re-synthesized by an expert panel made up of four physiotherapists, four secondary school teachers, and two school administrators. The instrument that emanated from the initial panel was further validated through a pilot study involving 20 secondary school students. The instrument was found to be comprehensible, but still required minor revisions and amendments which were carried out before the data collection commenced.

Ethical approval for the study was sought and obtained from the University of Ibadan/University College Hospital Health Research Ethics Committee (Protocol ID: UI/EC/12/0159). Approval was also obtained from the authorities of the various schools where the study was carried out. A letter seeking informed consent was distributed to the prospective participants in order to obtain 
Active Commuting to School as a Source of Health Promotion...

their parents'/guardians' consent. Assent/approval of the participants was equally obtained.

The questionnaire was used to obtain information on pattern, barriers, and facilitators of active commuting to school. Some of the questions included: by what means of transportation have you ever been to school in the last one month, which mode of transportation did you use most frequently in the last one month, how frequently did you use the transportation option to get to school in the past one month, why did you opt for your most frequent mode of transportation? Other questions on commuting and those related to sociodemographics are as shown in the attached copy of the questionnaire (appendix I). The students' home addresses were documented and these were used to estimate the distance travelled by each student to school. The question on amount paid as transport fare was used to substantiate the average distance between the student's home and school. Typically, a kilometre costs 20 naira on the average. The questionnaire was self-administered, and was retrieved immediately, except in cases where the respondent indicated that he/she would submit on a later date as a result of his/her schedule.

All continuous variables were summarized using descriptive statistics and presented in tables and charts. The students were grouped as active commuters (using only active modes such as walking and bicycling), semi-active commuters (combination of active and passive modes), and passive commuters (using only passive modes such as private or commercial vehicles, motorcycles and tricycles). The association between types of commuting and sociodemographic characteristics was determined using Chisquare analysis. The level of significance was set at $\mathrm{p}<$ 0.05 , and statistical analyses were conducted using the IBM SPSS Statistics version 20 (IBM Corporation, 2011).

\section{RESULTS}

A total of 926 students completed and returned the questionnaire. Close to one third $(64.9 \%)$ of the participants were between the ages of 13 and 15 years, and $70 \%$ (648) were female students (table 1). For majority $(52.7 \%$ ) of the students, the distance one way from their home to school was between 1 to $3 \mathrm{~km}$. Other details of the sociodemographic profile of the participants are presented in table 1 .
Table 1. Socio-demographic characteristics of the respondents

\begin{tabular}{|c|c|c|}
\hline Characteristics & $\mathrm{N}$ & $\%$ \\
\hline \multicolumn{3}{|l|}{ Age (yrs) } \\
\hline $10-12$ & 138 & 14.9 \\
\hline $13-15$ & 501 & 64.9 \\
\hline $16-18$ & 187 & 20.2 \\
\hline \multicolumn{3}{|l|}{ Sex } \\
\hline Male & 278 & 30 \\
\hline Female & 648 & 70 \\
\hline \multicolumn{3}{|l|}{ Type of school } \\
\hline Private & 406 & 43.8 \\
\hline Public & 520 & 56.4 \\
\hline \multicolumn{3}{|l|}{ Class of study } \\
\hline \multicolumn{3}{|l|}{ Junior Secondary } \\
\hline School (JSS) & 404 & 43.6 \\
\hline \multicolumn{3}{|l|}{ Senior Secondary } \\
\hline School (SSS) & 522 & 53.4 \\
\hline \multicolumn{3}{|c|}{ Approximate distance between home and school } \\
\hline$<1 \mathrm{~km}$ & 221 & 23.9 \\
\hline $1 \mathrm{~km}-<3 \mathrm{~km}$ & 488 & 52.7 \\
\hline $3 \mathrm{~km}-5 \mathrm{~km}$ & 112 & 12.1 \\
\hline$>5 \mathrm{~km}$ & 105 & 11.3 \\
\hline \multicolumn{3}{|c|}{ Father's employment status } \\
\hline Salaried employment & 538 & 58.1 \\
\hline Self employed & 388 & 41.9 \\
\hline \multicolumn{3}{|c|}{ Mother's employment status } \\
\hline Salaried employment & 342 & 36.9 \\
\hline Self-employed & 443 & 47.8 \\
\hline Unemployed & 97 & 10.5 \\
\hline Full housewife elite & 44 & 4.8 \\
\hline
\end{tabular}

Of the 926 participants, $183(19.8 \%)$ were active commuters, $105(11.3 \%)$ were semi-active commuters and $638(68.9 \%)$ were passive commuters. Most of the active commuters, $175(18.9 \%)$ walked while the rest $8(0.9 \%)$ cycled (figure 1). Of all the passive modes of transportation, public vehicles was the most widely used by $228(24.6 \%)$ of the students while the school bus was utilized by $66(7.1 \%)$ students. The students' attitude to active commuting is presented in table 2. Only $39(6.1 \%)$ of the passive commuters would actually have preferred to be active commuters, while 599 (93.9\%) preferred to remain as passive commuters. The majority, 442 (69.3\%) of the passive commuters still preferred to remain passive even after the question linking good health to active commuting. 


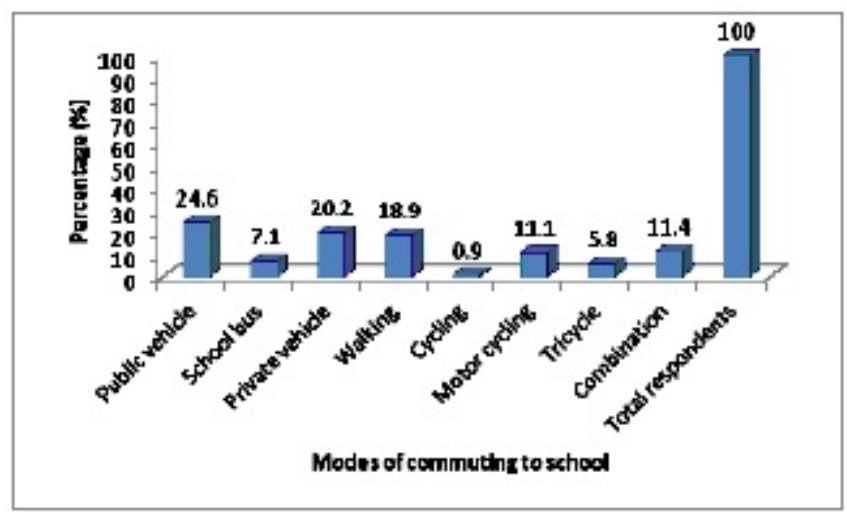

Figure 1. Details of active and passive modes of commuting.

Table 2. Attitude towards active commuting

\begin{tabular}{ll}
\hline Passive Commuters $(\mathbf{N}=\mathbf{6 3 8})$ & \\
Would have preferred to be active & Yes $[39(6.1 \%)]$ \\
commuters & No $[599(93.9)]$ \\
Would adopt active commuting for health & Yes $[196(30.7 \%)]$ \\
promotion & No $[442(69.3 \% 0]$ \\
Active Commuters $(\mathbf{N}=\mathbf{1 8 3})$ & \\
Commute alone & $24(12.9 \%)$ \\
Commute with siblings & $85(46.4 \%)$ \\
Commute with friends & $62(34.1 \%)$ \\
Commute with parents/older ones & $12(6.6 \%)$ \\
Most preferred mode of commuting $(\mathbf{N}=\mathbf{9 2 6})$ & \\
Private vehicle & $649(70.1 \%)$ \\
School bus & $82(8.9 \%)$ \\
Motorcycle & $44(4.8 \%)$ \\
Tricycle & $11(1.2 \%)$ \\
Public vehicle & $65(7.0 \%)$ \\
Cycling & $46(5.0 \%)$ \\
Walking & $29(3.0 \%)$ \\
\hline
\end{tabular}

Out of the 183 students who were active commuters, proximity of the school to their homes was the most reported facilitator of active commuting by 173 (94.5\%) of them (figure 2). This was followed by lack of transportation fare reported by 99 (54\%) students, while active commuting to school in order to exercise and be physically active was reported by only $19(10.4 \%)$ of the active commuters. Other facilitators of active commuting are presented in figure 2. While living near school was the most reported facilitator of active commuting, long distance between home and school was the most reported $(93.7 \%)$ barrier to active commuting among the passive commuters (figure 3). Lack of sidewalks along school roads was reported by 430 $(67.4 \%)$ of the students, while parental directive not to walk to school was reported by $387(60.8 \%)$ of the students. Issues such as unfavourable weather conditions, roadside crimes, need to get to school early and other reported barriers to active commuting are presented in figure 3.

The association between the sociodemographic characteristics of the students and their type of commuting is presented in table 3 . The types of commuting that were considered in this study were the active, semi-active and passive. It was observed that the types of commuting were significantly $(\mathrm{p}<0.05)$ associated with all the sociodemographic characteristics that were considered. The proportions of students who were actively commuting were observed to be higher among older adolescents (37.4\%), male students $(29.5 \%)$, those in junior secondary classes (22.5\%) and those living within $3 \mathrm{~km}$ of school (23.6\%). The proportion was also higher among public school students (20\%), whose fathers were self employed (32\%) and those whose mothers were unemployed (70.1\%). The breakdown of the proportions for semi-active and passive commuters is also presented in table 3 .

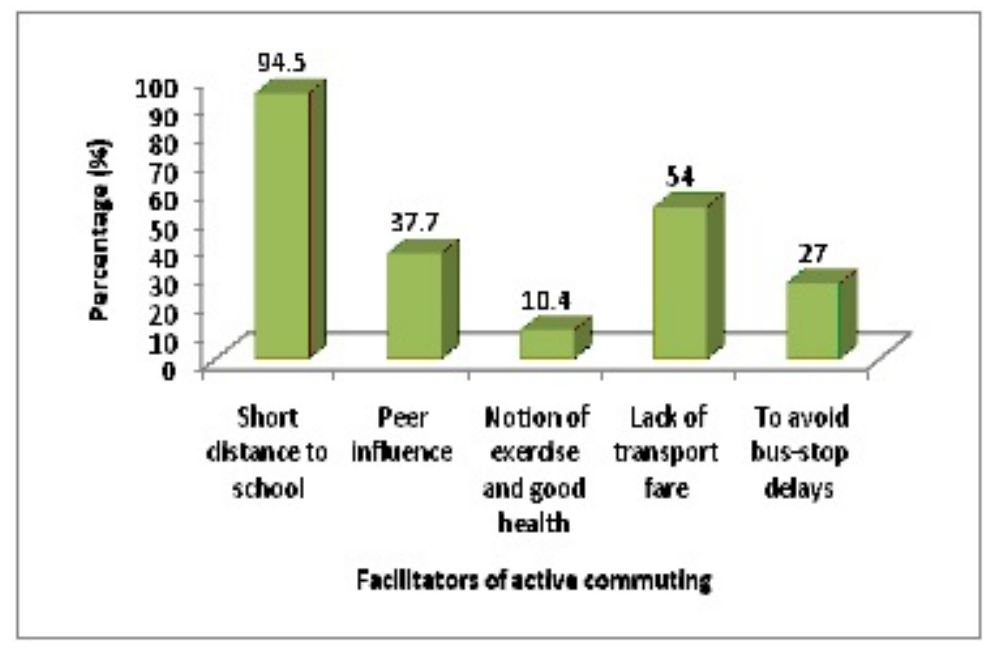

Figure 2. Facilitators of active commuting. 


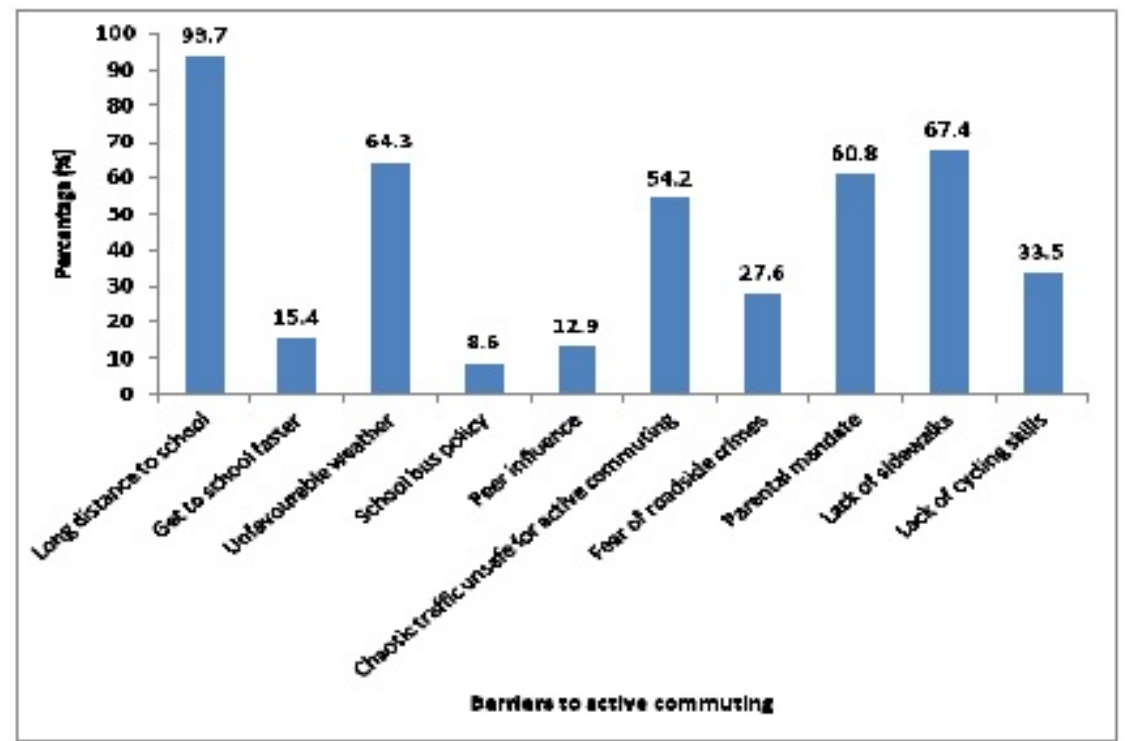

Figure 3. Barriers to active commuting.

Table 3. Association between sociodemographic characteristics and type of commuting to school

\begin{tabular}{|c|c|c|c|c|}
\hline & \multicolumn{3}{|c|}{ Type of Commuting } & \multirow[b]{2}{*}{$\chi^{2} \&$ p values } \\
\hline & $\begin{array}{c}\text { Active } \\
\mathrm{n}(\%)\end{array}$ & $\begin{array}{c}\text { Semi-active } \\
\mathrm{n}(\%)\end{array}$ & $\begin{array}{c}\text { Passive } \\
\mathrm{n}(\%)\end{array}$ & \\
\hline \multicolumn{5}{|l|}{ Age (Yrs) } \\
\hline $10-12$ & $24(17.4)$ & $11(8.0)$ & $103(74.6)$ & 319.1 \\
\hline $13-15$ & $89(14.8)$ & $15(2.5)$ & $497(82.7)$ & 0.00001 \\
\hline $16-18$ & $70(37.4)$ & $79(42.3)$ & $38(20.3)$ & \\
\hline \multicolumn{5}{|l|}{ Sex } \\
\hline Male & $82(29.5)$ & $65(23.4)$ & $131(47.1)$ & 97.19 \\
\hline Female & $101(15.6)$ & $40(6.2)$ & $507(78.2)$ & 0.00001 \\
\hline \multicolumn{5}{|l|}{ Type of school } \\
\hline Private & $32(7.9)$ & $16(3.9)$ & $358(88.2)$ & 125.5 \\
\hline Public & $151(29.0)$ & $89(17.1)$ & $280(53.9)$ & 0.00001 \\
\hline \multicolumn{5}{|l|}{ Class of study } \\
\hline \multicolumn{5}{|l|}{ Junior } \\
\hline secondary & $91(22.5)$ & $9(2.2)$ & $304(75.2)$ & 59.43 \\
\hline \multicolumn{5}{|l|}{ Senior } \\
\hline secondary & $92(17.6)$ & $96(18.4)$ & $334(64.0)$ & 0.00001 \\
\hline \multicolumn{5}{|l|}{ Distance } \\
\hline $0-3 \mathrm{~km}$ & $167(23.6)$ & $85(12.0)$ & $457(64.4)$ & 31.8 \\
\hline$>3 \mathrm{~km}$ & $16(7.4)$ & $20(9.2)$ & $181(83.4)$ & 0.00001 \\
\hline \multicolumn{5}{|c|}{ Father's employment status } \\
\hline \multicolumn{5}{|c|}{ Salaried } \\
\hline employment & $59(11.0)$ & $28(5.2)$ & $451(83.8)$ & 134.4 \\
\hline Self-employed & $124(32.0)$ & $77(19.8)$ & $187(48.2)$ & 0.00001 \\
\hline \multicolumn{5}{|c|}{ Mother's employment status } \\
\hline \multicolumn{5}{|l|}{ Salaried } \\
\hline employment & $47(13.7)$ & $27(7.9)$ & $268(78.4)$ & 251.7 \\
\hline Self-employed & $42(9.5)$ & $61(13.8)$ & $340(76.7)$ & $<0.00001$ \\
\hline Unemployed & $68(70.1)$ & $9(9.3)$ & $20(20.6)$ & \\
\hline \multicolumn{5}{|l|}{ Full housewife } \\
\hline elite & $26(59.1)$ & $8(18.2)$ & $10(22.7)$ & \\
\hline
\end{tabular}

\section{DISCUSSION}

This study was conducted to investigate the home-schoolhome commuting habits of a group of secondary school students from Nigeria and to identify the factors that serve as facilitators and barriers to active commuting among the students. The following observations were made: (i) majority of the students were passive commuters with only about one out of five identified as an active commuter, (ii) two-thirds of the students would prefer to stick with the passive mode of travelling even though the active mode is linked with health benefits, (iii) the facilitators of active commuting arranged in decreasing order from the most to the least prevalent include proximity of home to school, lack of transport fare, peer influence, bid to avoid bus-stop delays, and the notion of exercise and good health, (iv) the barriers to active commuting arranged in decreasing order from the most to the least prevalent include long distance between home and school, lack of sidewalks, unfavourable weather conditions, parental directive, chaotic traffic system that is unsafe for active commuting, lack of cycling skills, fear of roadside crimes, need to get to school faster, peer influence, and school bus policy, and (v) the sociodemographic characteristics of the students played significant roles in their commuting habits.

That the students were mainly passive commuters is not peculiar to Nigeria. The only difference between this observation and that of previous studies is the higher proportions of active commuters that were reported. In a Canadian study, up to $42.5 \%$ of high school students reported active commuting to school (Robertson-Wilson et 
al., 2008). Yeung et al (2008) also reported that one-third of school trips involved active commuting despite a commuting distance of $2.5 \mathrm{~km}$. Most of the students in the present study had a commuting distance of 1 to $3 \mathrm{~km}$ to school. This is because most parents enrolled their children in schools that meet their set standards, and in most cases, such schools are located far away from their homes.

Despite the widely acknowledged health benefits of active transport (Carver et al, 2013), it was observed that active commuting in this study was largely facilitated by the proximity of the home to school, and least facilitated by the notion of achieving good health through physical activity. This observation may need two quick interventions: one is to heavily orientate students to begin to see active commuting as a source of improved health, and the other is to make schools that meet the standards required by parents available within distances that may be perceived as short enough to allow for active commuting (Babey et al, 2009). The long distance between home and school makes parental chauffeuring a common practice (Carver et al, 2013) because those living furthest from their schools are likely to travel by passive means (Owen et al, 2012).

The high prevalence of passive commuting to school among the students in this study may reduce their physical activity level with attendant consequences for their health and wellbeing. According to Owen et al (2012), compared to children who walked or cycled to school, weekday physical activity was lower among children who travelled to school by car. Public vehicles appeared to be the most widely used by the participants in this study but Owen et al, (2012) had reported that individuals who used public vehicles were seen to have either similar or more physical activity than those who walked or cycled. The situation whereby higher physical activity is seen among public vehicle users compared to those who walked or cycled as pointed out by Owen et al (2012) is likely to be a feature of societies where traffic systems are highly regulated. In such societies, individuals will statutorily need to walk to terminuses or designated bus-stops before they can embark or disembark. In a typical Nigerian setting however, individuals can embark or disembark from a public vehicle in front of, or close to their home leading to reduced physical exertion.

That the majority of students in this study prefer passive commuting to school in private vehicles, and the fact that only a small fraction of them were actually willing to walk or cycle to school may be understandable. What is noteworthy is the fact that most of them still preferred the passive mode even after being informed of the health benefits inherent in active commuting. Although the reasons for this attitude were not sought in the questionnaire, a number of issues that may militate against their active commuting may be conjectured. For instance, a Nigerian study has shown that poor road use manners by drivers was the most important challenge school children face en-route to and from school in addition to safety and security concerns such as vehicular accidents and kidnapping (Ipingbemi \& Aiworo, 2013). Another challenge is the parental directive not to walk to school which was cited as a barrier by almost two-thirds of the students in this study. Concerns over the physical environment, including traffic density, poor provisions for pedestrians and cyclists, and child safety, often discourage parents from allowing their children to adopt active forms of travel (Hume et al, 2009; Jago \& Baranowski, 2004). It is therefore not surprising that most of the students in the present study were not in the habit of active commuting with their parents or older siblings. This attitude has a far reaching effect because it weakens role modelling in active commuting. In addition, a number of urban parents and guardians in Nigeria own personal cars and this has entrenched the "School Run" phenomenon in the language and routine of employees and employers of labour in Nigeria (Duze, 2010). This situation is not in favour of the "active commuting" campaign. The obligatory advance payment for school bus shuttle service that is reported in this study may also hamper active commuting as it is natural for a student who has paid for such services to utilize it. Lack of appropriate sidewalks and cycling skills were additional factors that discouraged active commuting among the students. These factors were also reported by Gropp et al (2012) and Ducheyne et al (2012).

More of the students who commuted actively were older adolescents, males, those living close to their schools, attending public schools, whose fathers were self-employed or whose mothers were unemployed. Usually, older students are more able to take charge of their activities than the younger ones and the parents are more comfortable leaving them to commute actively. Previous studies have also reported the link between these sociodemographic characteristics and active commuting to school among children and adolescents (Robertson-Wilson et al, 2008; Babey et al, 2009; Cui et al, 2011; Yeung et al, 2008). 
This study is of major public health significance because it has shown a potentially harmful trend and attitude in the commuting habits of typical Nigerian children and adolescents. One of the strengths of this study is that the few previous studies (Ipingbemi \& Aiworo, 2013; Duze, 2010) that were carried out in Nigeria were looking at commuting from the geographical and educational management viewpoint but this study is likely to be among the few, if any, that have looked at commuting of secondary school students from the physical activity and health points of view. Studies on commuting in sub-Saharan nations are few; hence this may serve as a reference point for similar environments. There is also a need to exercise caution when interpreting these results as it is not certain whether the pattern of commuting to school continued outside of school hours, and whether it was the same in the months preceding or after the data collection period.

\section{CONCLUSION}

This study found that the majority of the secondary school students in the study area were not actively commuting to school and most of them had an unreceptive attitude towards the adoption of active commuting, even when they were informed that it would improve their overall health. The facilitators of and barriers to active commuting among the students were presented and it is noted that active commuting to school may be improved if barriers can be mitigated. It may be particularly necessary to improve the standards of all schools so that travelling long distances to access perceived "good schools" for the children will be minimized thereby improving the popularity of active commuting to school.

\section{ACKNOWLEDGEMENTS}

The authors are sincerely indebted to all the students who took part in the study, to their parents for giving the required consent, and to the various school authorities for allowing the questionnaire to be distributed among their students.

\section{Conflict of Interest}

There was no conflict of interest.

\section{References}

Babey, S.H., Hastert, T.A., Huang, W., and Brown, E.R. (2009). Sociodemographic, family, and environmental factors associated with active commuting to school among US adolescents. Journal of Public Health Policy, 30: S203-S220.

Carver, A., Timperio, A. and Crawford, D. (2013). Parental chauffeurs: what drives their transport choice? Journal of Transport Geography, 26: 72-77.

Chillón, P., Ortega, F.B., Ruiz, J.R., Veidebaum, T., Oja, L., Mäestu, J. and Sjöström, M. (2010). Active commuting to school in children and adolescents: an opportunity to increase physical activity and fitness. Scandinavian Journal of Public Health, 38: 873-879.

Cui, Z., Bauman, A. \& Dibley, M.J. (2011). Temporal trends and correlates of passive commuting to and from school in children from 9 provinces in China. Preventive Medicine, 52: 423-427.

Ducheyne, F., De Bourdeaudhuij, I., Spittaels, H. and Cardon, G. (2012). Individual, social and physical environmental correlates of 'never' and 'always' cycling to school among 10 to 12 year old children living within a $3.0 \mathrm{~km}$ distance from school. International Journal of Behavioral Nutrition and Physical Activity 9.

Duze, C.O. (2010). Average distance travelled to school by primary and secondary school students in Nigeria and its effect on attendance. African Research Review 4: 378-388.

Gropp, K.M., Pickett, W. and Janssen, I. (2012). Multi-level examination of correlates of active transportation to school among youth living within 1 mile of their school. International Journal of Behavioral Nutrition and Physical Activity 9: doi:10.1186/1479-5868-9-12.

Hume, C., Timperio, A., Salmon, J., Carver, A., Giles-Corti, B. and Crawford, D. (2009). Walking and cycling to school: predictors of increases among children and adolescents. American Journal of Preventive Medicine, 36: 195-200.

Ipingbemi, O. and Aiworo, A.B. (2013). Journey to school: safety and security of school children in Benin City, Nigeria. Transportation Research Part F: Traffic Psychology and Behaviour, 19: 77-84.

Israel, G.D. (2012). Sampling the evidence of extension program impact. Program Evaluation and Organizational Development, IFAS, 1992 University of Florida. PEOD-5. http://edis.ifas.ufl.edu/pd005. Accessed on15 February, 2012.

Jago, R. and Baranowski, T. (2004). Non-curricular approaches for increasing physical activity in youth: a review. Preventive Medicine, 39: 157-163.

Lee, M.C., Orenstein, M.R. and Richardson, M.J. (2008). Systematic review of active commuting to school and children's physical activity and weight. Journal of Physical Activity and Health, 5: 930-949. 
Mendoza, J.A., Watson, K., Nguyen, N., Cerin, E., Baranowski, T. and Nicklas, T.A. (2011). Active commuting to school and association with physical activity and adiposity among US youth. Journal of Physical Activity and Health, 8: 488-495.

Owen, C.G., Nightingale, C.M., Rudnicka, A.R., Sluijs, E.M., Ekelund, U., Cook, D.G. and Whincup, P.H. (2012). Travel to School and Physical Activity Levels in 9-10 Year-Old UK Children of Different Ethnic Origins-Child Heart and Health Study in England (CHASE). PLOS ONE 7.

Pizarro, A.N., Ribeiro, J.C., Marques, E.A., Mota, J. and Santos, M.P. (2013). Is walking to school associated with improved metabolic health? International Journal of Behavioral Nutrition and Physical Activity 10.

Robertson-Wilson, J.E., Leatherdale, S.T. and Wong, S.L. (2008). Social-ecological correlates of active commuting to school among high school students. Journal of Adolescent Health 42: 486-495.
Rodríguez-López, C., Villa-González, E., Pérez-López, I.J., Delgado-Fernández, M., Ruiz, J.R. and Chillón, Y.P. (2013). Family factors influence active commuting to school in Spanish children. Nutricion Hospitalaria 28: 756-763.

Tomori, M.A. (2013). Ibadan metropolitan area and the challenges to sustainable development. http://macosconsultancy.com. Accessed on 11 November, 2013.

Tudor-Locke, C., Ainsworth, B.E. and Popkin, B.M. (2001). Active commuting to school: an overlooked source of children's physical activity? Sports Medicine 31: 309-313.

Yeung, J., Wearing, S. and Hills, A.P. (2008). Child transport practices and perceived barriers in active commuting to school. Transportation Research Part A: Policy and Practice 42: 895-900. 
Appendix I

\section{ACTIVE COMMUTING QUESTIONNAIRE}

This questionnaire is designed to find out how secondary school students commute to school in a typical urban area of Nigeria, the relative numbers that use a particular transportation option and the factors that influence such choices. This is NOT A TEST, and there are no right or wrong answers. Please answer each question as honestly and accurately as you can.

Questionnaire no:

\section{Section A}

1. Age (at last birthday): ............

2. Sex: $M / F$

3. Class:

4. Location where school is sited:

5. Location where residence is sited:

6. Parents' Occupation

Father:

Mother:

7. How much on the average does it cost to get to your school by commercial bus?

8. By what means of transportation have you ever been to school in the last one month? (Tick as many as apply here )
a) Public vehicle
f) Motorcycle (Okada)
b) School bus
g) Tricycle (Keke NAPEP)
c) Private vehicle
h) Combination (of walking, motor
d) Walking vehicle/okada etc)
e) Cycling
i) Others? (please specify)

9. Which mode of transportation did you use most frequently in the last one month? (Tick only one option; the most frequently used)
a) Public vehicle
f) Motorcycle (Okada)
b) School bus
g) Tricycle (Keke NAPEP)
c) Private vehicle
h) Combination (of walking, motor
d) Walking vehicle/okada, etc.)
e) Cycling
i) Others? (please specify)

10. How frequently did you use the transportation option chosen in 9 above to get to school in the past one month?
a) 5 days a week
b) 4 days a week
c) 3 days a week and below

11. If your most frequent mode of transportation was either walking or cycling, why did you opt for any of these modes of transportation? (Tick all relevant reasons)
a) Short distance between home and school
h) Lack of access to other means
b) Long distance between home and school
i) Lack of transport fare
c) In order to get to school faster
j) My parents make me use it
d) Unfavourable weather conditions
k) For exercise and good health
e) Because my friends use it
f) To avoid bus-stop delays
l) I don't know
m) Others? (please specify)

g) Unsafe traffic conditions on the roads 
12. If your most frequent mode of transportation was any other than walking or cycling, why did you not consider walking or cycling? (Tick all relevant reasons)
a) Short distance between home and school
h) High crime rate in the street
b) Long distance between home and school
i) Lack of access to other means
c) In order to get to school faster
j) Lack of road sidewalks
d) Unfavourable weather conditions
k) Lack of cycling skills
e) School bus policy
1) My parents make me use it
f) Because my friends use it
m) I don't know
g) Unsafe traffic conditions on the roads
n) Others? (please specify)

\section{Section B}

(Please answer this section only if you indicated earlier in section A that you usually go to school by any means other than walking and/or cycling. Otherwise skip and move to Section C)

13. Would you have preferred to walk or ride a bicycle to school if you had the opportunity?

$$
\text { Yes } \square \quad \text { No } \square
$$

14. If you were told that walking or cycling to school is good for your health, would you make effort to adopt any of the two?

Yes $\square \quad$ No

\section{Section C}

(Please answer this section only if you indicated earlier in Section A that you usually walk or cycle to school. Otherwise skip and continue on to Section D)

15. Do you have any walk buddy for your walk or cycle to and from school?
a) Alone
b) With Siblings
c) With Friends
d) With parent or older relative

16.

If you had the option of going to school by other means apart from walking or cycling, would you still have preferred to walk or cycle?

Yes

No

\section{SECTION D}

17. Regardless of your current mode of transport, please rate your preference for the following modes of transportation to school by ticking the appropriate box (Tick only once for each option)

$$
\text { Most preferred Least preferred Not desired }
$$

Private vehicle
School bus
Motorcycle (Okada)
Tricycle (Keke NAPEP)
Public vehicle
Cycling
Walking

This is the end of the questionnaire. Thank you for your time! 